\title{
« Du couscous et des meetings contre l'émigration clandestine ». Mobiliser sans protester au Sénégal
}

Thèse de Doctorat $(\mathrm{PhD})$, université Paris 1, département de science politique, Centre européen de sociologie et de science politique (CESSP), 2017, 827 p. (2 vol.)

\section{Emmanuelle Bouilly}

\section{(2) OpenEdition}

\section{Journals}

Édition électronique

URL : http://journals.openedition.org/anthropodev/888

DOI : 10.4000/anthropodev.888

ISSN : 2553-1719

Éditeur

Presses universitaires de Louvain

\section{Édition imprimée}

Date de publication : 1 décembre 2019

Pagination : 171-172

ISBN : 978-2-87558-940-8

ISSN : 2276-2019

Référence électronique

Emmanuelle Bouilly, " «Du couscous et des meetings contre l'émigration clandestine ». Mobiliser sans protester au Sénégal », Anthropologie \& développement [En ligne], 50 | 2019, mis en ligne le 16 juin 2020, consulté le 25 janvier 2021. URL : http://journals.openedition.org/anthropodev/888 ; DOI : https://doi.org/10.4000/anthropodev.888

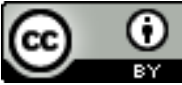

La revue Anthropologie \& développement est mise à disposition selon les termes de la Licence Creative Commons Attribution 4.0 International. 


\title{
"Du couscous et des meetings contre l'émigration clandestine ". Mobiliser sans protester au Sénégal
}

\author{
Emmanuelle Bouilly ${ }^{1}$ \\ Thèse de Doctorat $(P h D)$, université Paris 1 , département de science \\ politique, Centre européen de sociologie et de science politique \\ (CESSP), 2017, 827 p. (2 vol.)
}

\begin{abstract}
Ce travail s'inscrit dans un contexte particulier : celui du gouvernement des migrations internationales marqué par la fermeture des frontières de l'Union européenne aux populations venues notamment d'Afrique. II a pour objet principal une mobilisation apparue en 2006 au Sénégal dont l'objectif est officiellement "de lutter contre l'émigration clandestine ". Elle est animée par des femmes dont les fils ou les proches sont morts alors qu'ils émigraient en Europe en traversant l'Atlantique à bord de pirogues. Cette mobilisation est triplement originale : par le statut de ses actrices - des leftbehind ; par sa cause atypique dans un pays où la migration est ancienne et valorisée ; par sa forme - une association revendicative également groupe de parole, mutuelle de crédit et coopérative de travail où les adhérentes réalisent des actions d'entraide, des activités artisanales et commerciales, des campagnes de sensibilisation, et des témoignages publics critiques. Cette thèse s'attache à saisir ce que signifie empiriquement et théoriquement une mobilisation qui consiste à " faire du couscous et des meetings contre l'émigration ", selon les termes d'une enquêtée.
\end{abstract}

À partir d'une enquête de 15 mois combinant observations ethnographiques, entretiens en wolof et en français, archives et analyse statistique, ce travail montre qu'il existe des mobilisations non protestataires qui pour autant ne sont pas infra-politiques. En effet, les conceptions légitimistes du " bon " mouvement social tendent à invisibiliser - en Afrique comme ailleurs - certaines formes d'action collective et de représentation politique qui ne ciblent pas l'État et ne recourent pas à l'action protestataire. Cette thèse soutient que mobiliser n'est pas protester : une action collective ne s'accompagne pas toujours d'une contestation -au sens de discours conflictuel et vindicatif-, qui elle-même ne s'accompagne pas toujours d'une protestation - un répertoire d'action confrontatif.

\footnotetext{
${ }^{1}$ E-mail : e.bouilly@sciencespobordeaux.fr
} 
Dans le cas étudié, l'évitement de la protestation s'explique par trois facteurs principaux : le genre, le patronage et clientélisme, et l'action publique internationale. Tout d'abord, les rapports de genre, imbriqués dans des rapports d'aînesse, ont déterminé l'engagement individuel et les formes et motifs de la lutte. Pour faire face aux conséquences dramatiques des départs qu'elles avaient encouragés, ces femmes ont opté pour des modes d'organisation et d'action qui leur sont familiers et accessibles, répondent à leurs besoins et reposent sur leurs savoir-faire et réseaux genrés. Ensuite, le patronage et le clientélisme ont des effets ambivalents sur la mobilisation. Alors que les relations de don/contre-don entre membres et porte-parole annihilent la délibération et la contestation en interne, l'accès routinisé aux patrons politiques rend souvent trop coûteux le passage à la protestation. En revanche, ce dernier autorise parfois l'expression d'un discours public critique où les dominants sont rappelés à leur rôle. Les responsables politiques et l'État sont en outre eux-mêmes des instigateurs de mobilisation. Ils s'appuient sur des courtiers pour drainer une foule de participants à des rassemblements divers allant des meetings électoraux aux fêtes nationales. Historiquement centrales dans cette division du travail politique, les femmes ont développé des " arts de faire mobilisation » bien rodés, arrimés au parti-État. Or, les acteurs de l'aide internationale et du développement s'adossent couramment à ces techniques et entrepreneures de mobilisation pour mener à bien leurs programmes. À rebours des thèses sur la dépolitisation des luttes et l'assujettissement des subalternes, ce travail montre pour finir que l'action développementiste renforce plus qu'elle n'impose des mobilisations qui évitaient déjà toute protestation contre l'État. 